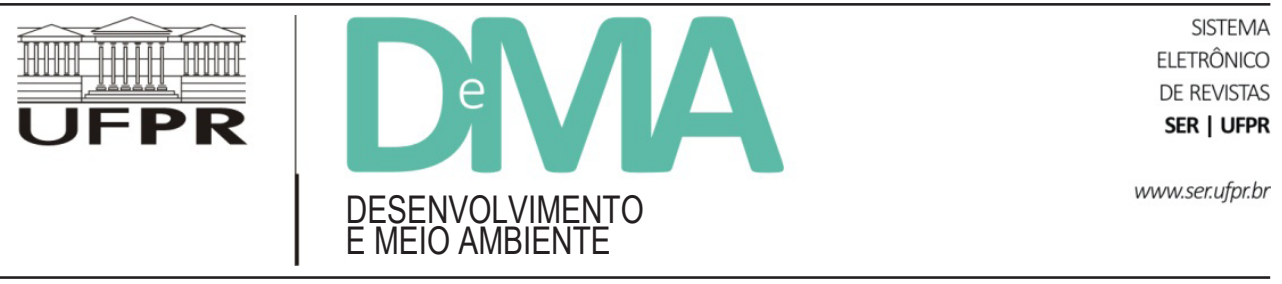

\title{
Gênero, agroecologia e economia solidária: estudo de caso do grupo de mulheres do Acampamento Recanto da Natureza em Laranjeiras do Sul - PR
}

\section{Gender, Agroecology and Solidary Economy: A Case Study of the Women's Group of Recanto da Natureza Camp in Laranjeiras do Sul - PR}

\author{
Flávia Regina Fernandes SILVA ${ }^{1 *}$ \\ ${ }^{1}$ Programa de Pós-Graduação em Agroecologia e Desenvolvimento Rural Sustentável (PPGADR), Universidade Federal da Fronteira Sul \\ (UFFS), Laranjeiras do Sul, PR, Brasil. \\ *E-mail de contato: flaviabux@gmail.com
}

Artigo recebido em 2 de março de 2016, versão final aceita em 2 de dezembro de 2016.

RESUMO: A lógica produtivista e mercadológica dominante no processo de modernização do campo, reforçada por políticas neoliberais, além de causar danos ao meio ambiente, modificou os processos de produção e consumo do alimento e aumentou a pobreza e a exclusão social, sendo as mulheres as mais afetadas nesse processo. No entanto, dentro desse cenário, vêm surgindo novas estratégias, como a agroecologia e a economia solidária, que estão possibilitando às famílias agricultoras camponesas continuar resistindo e existindo no campo, com as mulheres sendo protagonistas dessas políticas alternativas de sustentabilidade. O presente artigo visa refletir sobre a importância da participação das mulheres camponesas em grupos produtivos, que adotam a agroecologia como estratégia de desenvolvimento local, a fim de possibilitar maior inclusão da questão de gênero nessa discussão. Para tal, realizou-se uma pesquisa qualitativa baseada em dados retirados de entrevistas coletadas com homens e mulheres membros do grupo de agroecologia do Acampamento Recanto da Natureza em Laranjeiras do Sul (PR), do Movimento dos Trabalhadores Rurais Sem Terra (MST). A pesquisa evidencia a importância da participação das mulheres para o desenvolvimento e o fortalecimento da comunidade, assim como para a autonomia econômica e política delas, favorecendo seu empoderamento e a ressignificação identitária. Ao mesmo tempo, busca-se problematizar a sobrecarga de trabalho acumulado, fruto da naturalização da ideia de que o trabalho doméstico é apenas responsabilidade das mulheres, o que dificulta maiores avanços na construção de uma comunidade mais equitativa e sustentável.

Palavras-chave: mulheres; agroecologia; soberania alimentar; economia solidária.

ABSTRACT: The dominant productivist and market logic in the countryside modernization process, reinforced by neoliberal policies, caused damage to the environment, modified the production and food consumption processes and increased the poverty and social exclusion, with women being the most affected ones in this process. However, 
new strategies are emerging in this scenario, such as agroecology and solidary economy, that are enabling the peasant farming families to resist and to exist in the rural communities, with women being protagonists of these alternative policies for sustainability. This article aims at reflecting on the importance of the participation of rural women in productive groups, which adopt agroecology as a local development strategy, in order to enable greater inclusion of the gender issue in this discussion. To this end, a qualitative research was done, based on data drawn from collected interviews with men and women, members of the agroecology group of Recanto da Natureza Camp, in Laranjeiras do Sul (PR), from the Landless Workers Movement (MST). The research highlights the importance of women's participation in the development and strengthening of the community as well as in their economic and political autonomy, promoting their empowerment and identity reinterpretation. At the same time, it brings up the question of the accumulated workload, as a result of the naturalization of the idea that housework is just women's responsibility, which hinders the building of a more equitable and sustainable community.

Keywords: women; agroecology; food sovereignty; solidary economy.

\section{Introdução}

A modernização do campo trouxe consequências devastadoras para o meio ambiente e para a economia das pequenas unidades familiares ali existentes, alterando a organização da sociedade, com o crescente êxodo rural das famílias, além de modificar o viver daqueles que conseguiram resistir ao avanço do agronegócio e permaneceram em suas unidades de produção familiar.

Partindo de interesses mercadológicos, a modernidade - com destaque para a área rural - debruçou-se no aumento da capacidade de produção. Com base no discurso sobre o combate à fome no mundo, que passa a ser uma das grandes justificativas para tais alterações, eclodiu-se a Revolução Verde caracterizada pela intensificação de insumos químicos, máquinas e equipamentos para o incremento da produção agrícola (Costabeber, 2007).

Campos (2011) afirma que o agronegócio, representante maior do progresso no campo, cresce junto e, não por coincidência, no mesmo contexto da pobreza e da exclusão social. Ambos ganharam força em decorrência das políticas neoliberais adotadas pelo mundo e pelo Brasil a partir da década de 1990. Tais políticas, à medida que favoreceram a concentração de renda, por meio de estratégias de desenvolvimento como o agronegócio, aumentaram e agravaram a pobreza e a exclusão no país.

Mesmo dentro desse cenário que não respeita os limites dos ecossistemas e o saber dos camponeses e dos povos tradicionais - os mais afetados no atual modelo -, estes continuam existindo e resistindo no campo. Constroem novas formas de manter-se produzindo tanto para a subsistência quanto para comercialização de seu excedente em feiras e outros tipos de mercados curtos, o que vem proporcionando maior fôlego e garantindo a permanência dessas famílias no meio rural. As mulheres rurais aparecem como sujeitos importantes na luta pela transformação social e pela proteção e preservação do meio ambiente e da cultura dos povos camponeses e tradicionais, contribuindo para uma maior sustentabilidade da vida.

Sevilla-Guzman (2012) aponta que, com a ampliação dos mercados, os sistemas produtivos industriais aproveitaram-se do desenvolvimento do transporte de longas distâncias, das novas formas de tecnologia de informação e da precarização das relações de trabalho para estender seus tentáculos a vários âmbitos de produção e comercialização. Isso acabou por impor, dentre muitas outras coisas, 
o controle das multinacionais sobre a produção e os mercados, evidenciando que a indisponibilidade dos bens de consumo - os alimentares, por exemplo - está ligada à forma como a sociedade está organizada, condicionada a fatores de natureza econômica.

Atualmente, as grandes empresas multinacionais agem como reguladores do mercado, afetando a soberania dos países e colocando sua população à mercê dessas empresas na gana por mais lucros. Essa atual condição afeta toda a cadeia produtiva, o que impacta não só o produtor, mas também o consumidor:

O impacto econômico deste processo é simples: do lado do produtor, o lucro é insuficiente para desenvolver, ampliar ou aperfeiçoar a produção, e em consequência a oferta não se expande. Do lado do consumidor, o preço é muito elevado, o que faz com que o consumo também seja limitado. Quem ganha é o intermediário, com margens muito elevadas sobre um fluxo relativamente pequeno de produto (Dowborn, 2014, p. 8).

Há, portanto, um aumento de investimento no modelo tecnológico baseado no produtivismo, com a introdução cada vez mais intensa de elementos danosos ao meio ambiente, como as sementes transgênicas e os agroquímicos. A agricultura tratada como mercadoria reforça os processos de apropriação e substituição das culturas dos povos pelo domínio cada vez maior das empresas de insumos e da indústria de transformação alimentar (Sevilla-Guzmán, 2012).

Nessa mesma perspectiva de análise, Campos (2011) aponta que a lógica do mercado e da racionalidade científica como parâmetro para a modernização agrícola manteve a tradicional divisão sexual do trabalho e reduziu a importância e o espaço de trabalho da mulher. Isso foi apontado como uma das causas para a redução maior da população feminina no campo em relação à masculina. A grande oferta de alimentos no mercado culminou numa redução do autoconsumo e do trabalho feminino no roçado, assim como na preferência pela compra de sementes e mudas em detrimento da aquisição no interior da propriedade, mediante colheita e secagem próprias. Todos esses fatores evidenciam que as mulheres foram as principais afetadas diante de tal cenário.

A superação das políticas concentradoras de riqueza, favorecedoras da desigualdade e da devastação que esse modelo produz, exige ações que alterem a lógica atual dominante. É preciso mudar esse paradigma voltado para o mercado para colocar em primeiro plano o cuidado da vida humana e do meio ambiente. Essa outra perspectiva exige novas formas de relações, ligadas à solidariedade e à cooperação, incluindo a questão de gênero, ou seja, tornando visível a participação das mulheres nesses processos de resistência e mudanças.

Faria (2011) afirma que, como resposta às políticas concentradoras de riqueza e acentuadoras de desigualdade adotadas pelo país, alternativas para superar a pobreza e o desemprego estruturais começaram a surgir no final dos anos 1990 no Brasil, por meio de cooperativas, grupos de comercialização, de produção e de créditos. Aparece, então, nesse processo, o debate sobre economia solidária, que abriu um espaço para discussão da economia baseada na solidariedade, na cooperação e na reciprocidade, construindo práticas contra-hegemônicas. Isso contribuiu para a crítica à economia dominante, uma vez que se evidenciou que outros elementos não mensurados na economia mercantil tinham papel importante para a vida das pessoas.

A economia solidária, segundo afirma Singer (2000), é uma tentativa de organização socioeconômica, buscando uma relação mais solidária entre 
produtores e consumidores, estruturada por associações ou cooperativas. Busca, fundamentalmente, criar alternativas de geração de renda e combate ao desemprego para as populações mais pobres e mais largamente afetadas pelo modelo neoliberal.

Essa alternativa ainda não está pronta e isso se evidencia nas fortes críticas tecidas por autores como Gaiger (2003), Germer (2006) e Sousa \& Neves (2011), de que a economia solidária é uma estratégia adaptativa de inserção dos mais pobres nas novas necessidades do capitalismo atual, que pouco tem promovido o emprego estável. Apoiada por movimentos sociais, ONGs e até pelo Estado brasileiro, por meio da Senaes, ${ }^{1}$ essa forma de organização do trabalho não consegue existir para além do poder do capital.

Mas, de maneira geral, para esses autores, a economia solidária ajudou a formalizar as associações e cooperativas de trabalhadores que buscavam coletivamente tocar e gerir empreendimentos produtivos de forma cooperada, solidária e democrática, mediante trocas, trabalhos voluntários e reciprocidade, o que em si proporciona maior satisfação e identificação entre os trabalhadores e seu trabalho, além de trazer como vantagem a apropriação, pelos próprios trabalhadores, dos excedentes produzidos e a diminuição da exploração capitalista sobre eles.

Surge, portanto, a necessidade de incorporar à proposta da economia solidária outros elementos que visem a uma mudança social mais ampla, capaz de construir "um outro modelo econômico, voltado para a garantia do bem-estar e não do lucro. A economia camponesa, o papel da agricultura familiar e da agroecologia formam parte desse debate" (Faria, 2011. p. 42).

A agroecologia e o modo de vida camponês apresentam, por meio da luta pela soberania ali- mentar, uma alternativa às políticas neoliberais e ao que chamam de mercantilização da vida, na qual os elementos essenciais à sobrevivência humana, como a alimentação, estão sob o domínio do capital. Entende-se por soberania alimentar:

\begin{abstract}
o direito dos povos definirem suas próprias políticas e estratégias sustentáveis de produção, distribuição e consumo de alimentos que garantam o direito à alimentação para toda a população, com base na pequena e média produção, respeitando suas próprias culturas e a diversidade dos modos camponeses, pesqueiros e indígenas de produção agropecuária, de comercialização e gestão dos espaços rurais, nos quais a mulher desempenha um papel fundamental [...]. A soberania alimentar é a via para erradicar a fome e a desnutrição e garantir a segurança alimentar duradoura e sustentável para todos os povos (Fórum Mundial sobre Soberania Alimentar. 2001 apud Maluf. 2007, p. 23).
\end{abstract}

Freitas (2008) afirma que defender a soberania alimentar é priorizar a produção agrícola local e o acesso dos camponeses à terra, aos recursos naturais e ao crédito, além de reconhecer o papel essencial das camponesas na produção agrícola e na alimentação e incorporar à sua luta as demandas das organizações de mulheres que se dedicam à preparação de alimentos e lutam pelo estabelecimento de um comércio internacional justo. Portanto, além de possibilitar um protagonismo social dos povos, há um resgate da biodiversidade e da cultura dos povos camponeses e tradicionais que têm sido dizimados ao longo dos processos de globalização dos mercados.

Dessa forma, a agroecologia busca explorar conhecimentos e métodos ecológicos modernos ao mesmo tempo em que mantém os aspectos de conservação dos recursos da agricultura tradicional

\footnotetext{
1 Secretaria Nacional de Economia Solidária, ligada ao Ministério do Trabalho e Previdência Social.
} 
local. Ela é uma ciência que "proporciona o conhecimento e a metodologia necessários para desenvolver uma agricultura que é ambientalmente consistente, altamente produtiva e economicamente viável" (Gliessman, 2009, p. 56). Nela, o conhecimento local e empírico dos agricultores e a forma como socializam e aplicam esse conhecimento na construção da sustentabilidade são levados em consideração.

A agroecologia vem resgatar a importância do modo de vida camponês como meio de produzir agricultura de forma a preservar o meio ambiente. O camponês, por sentir-se parte da natureza, apresenta forma de manejo dos recursos naturais diferenciada, com integração e apego à terra e aos cultivos (Sevilla-Guzmán \& Molina, 2013). Tem como estratégia a valorização dos recursos internos que ficam voltados para garantir a sobrevivência da unidade familiar.

Assim, a agroecologia tem se apresentado como uma importante estratégia de desenvolvimento rural para os agricultores familiares que a têm adotado como sistema produtivo. Ao propor formas de manejo ecológico dos recursos naturais, a partir de propostas participativas de produção e circulação alternativa do produto, estabelece formas de produção e consumo que contribuem para enfrentar a destruição do meio ambiente e a exclusão social geradas pelo neoliberalismo atual (Sevilla-Guzmán, 2007).

Aliada ao campesinato, a estratégia de desenvolvimento rural da agroecologia possibilita a criação de vários espaços de trabalho, coletivos e solidários que visam, além da inserção econômica por meio de mercados curtos, minimizar a penosidade do trabalho no campo e promover a preservação do meio ambiente, ao mesmo tempo em que busca integrar, dentro dos processos produtivos, todos os seus membros: homens, mulheres e jovens (Sevilla-Guzmán \& Montiel, 2009).
Um bom exemplo dessa articulação se faz presente na Rede Ecovida de Agroecologia. Segundo Rover \& Lampa (2013), a Rede Ecovida, criada em 1998, na região Sul, apresenta-se como uma exitosa alternativa ao modelo de agricultura dominante. Busca estabelecer comercialização direta, local e regional, dos produtos da agricultura agroecológica, eliminando ao máximo os intermediários. Divide-se em núcleos regionais independentes espalhados na região, os quais têm uma organização descentralizada e democrática, de maneira que cada região toma suas decisões de comercialização com base na sua forma local de produzir e comercializar.

A própria Rede Ecovida é responsável pela certificação participativa de produtos orgânicos, com compromisso tanto dos agricultores quanto dos seus consumidores, aproximando-os de forma solidária e construindo um laço social de credibilidade. Assim, nesse processo, os indivíduos tornam-se sujeitos de sua história, já que as decisões são tomadas a partir da organização do grupo, estando eles próprios responsáveis pelo destino a ser seguido.

O foco da Rede Ecovida é a abertura de mercados alternativos, como feiras locais e regionais, e, quando estes se apresentam limitados para a oferta dos produtos locais, possibilita-se o acesso ao Circuito Sul de circulação de alimentos da Rede Ecovida de Agroecologia, onde há estações-núcleos que são pontos de reunião, troca e distribuição de produtos entre os diferentes núcleos da rede. Tudo isso é proporcionado pela autonomia e pela auto-organização dos agricultores e consumidores estruturados em uma rede solidária (Rover \& Lampa, 2013).

Mas, mesmo dentro de espaços organizados como o da Rede Ecovida, a invisibilidade das mulheres ou a sua pouca participação na esfera produtiva, ligadas às desigualdades de gênero, têm se mostrado danosas à agroecologia, por tornar 
inviável a contribuição de quase metade da população do campo, que tanta experiência tem sobre uma produção limpa, sustentável e que ajuda nos processos de saúde.

Siliprandi (2013) aponta que tem acontecido, recentemente, uma importante valorização das experiências vividas nas comunidades e uma constante preocupação com a alimentação saudável e com a saúde das pessoas e do ambiente, e tudo isso começa a fazer parte da discussão sobre desenvolvimento rural sustentável. Nessa discussão, abrem-se oportunidades políticas no campo da alimentação, possibilitando importante brecha para a discussão da questão de gênero e o empoderamento das mulheres no processo de produção agrícola.

Dessa maneira, reconhecê-las como sujeitos e atrizes fundamentais no resguardo da alimentação da família e na preservação de práticas tradicionais pode provocar mudanças significativas na organização social do trabalho e no papel dos gêneros na produção e na reprodução da vida. Portanto, o propósito de um desenvolvimento rural sustentável, baseado na agroecologia e na soberania alimentar, além de se opor ao modelo da Revolução Verde, pretende também desestabilizar o discurso patriarcal sobre o qual a sociedade está alicerçada (Faria \& Moreno, 2008).

Portanto, um desenvolvimento plenamente sustentável para o campo, segundo Siliprandi (2007), exige mudanças sociais e políticas de busca da equidade, da solidariedade e da inclusão social. Entre elas, as mudanças nas relações de gênero. Para uma melhor compreensão desse processo, foi feito o questionamento de como a escolha pela agroecologia pode afetar a vida das mulheres e se isso contribui ou não para o empoderamento delas. Para tal, foi proposto um estudo de caso sobre o Acampamento Recanto da Natureza, em Laranjeiras do Sul (PR).
O Recanto da Natureza é um acampamento do Movimento dos Trabalhadores Rurais Sem Terra (MST) que tem características peculiares quanto à forma de organização do trabalho em mutirão, cooperativas e associações (Morissawa, 2001; Christoffoli, 2015). Em sua maioria, as famílias do acampamento optaram pela produção agroecológica e pela inclusão das mulheres de forma mais direta na organização do grupo e no trabalho coletivo. Essa nova configuração do coletivo no acampamento possibilitou a inserção delas no trabalho na agroindústria que fabrica pães e biscoitos orgânicos e/ou agroecológicos.

A partir da pesquisa de mestrado, foi possível perceber que esse formato de coletivo tende a destacar a participação das mulheres camponesas nos grupos produtivos que adotam a agroecologia como estratégia de desenvolvimento local e como uma alternativa importante de conquista de sua autonomia econômica e política. A pesquisa também buscou compreender o grupo de mulheres em relação às suas demandas particulares de produção e de existência, a fim de verificar como ocorre a inclusão da questão de gênero no processo de desenvolvimento local que tem por base a agroecologia como forma de produção.

\section{Materiais e métodos}

Essa pesquisa se fez por meio de um estudo de caso de um grupo produtivo de mulheres no Acampamento Recanto da Natureza, situado no município de Laranjeiras do Sul, Paraná. O levantamento dos dados foi realizado entre os meses de julho e setembro de 2015.

O acampamento Recanto da Natureza tem uma história de luta pela terra e de resistência de longos anos. Foi iniciado em 1999, quando um grupo de 27 famílias, ligado ao MST, ocupou a área em que está 
atualmente. Passaram-se 16 anos sem que o poder público efetivasse a área para a reforma agrária, o que impede o acesso dos moradores às políticas públicas de reforma agrária.

O grupo estudado é composto de dez mulheres agricultoras que têm a agroecologia como estratégia de produção. Entende-se por grupo produtivo uma organização de mulheres que se reúnem, dividem o trabalho, realizam-no coletivamente e comercializam os produtos. Esse grupo foi escolhido por já estar em processo de consolidação de suas práticas e processos relacionais, organizado e atuante na região de Laranjeiras do Sul, pela escolha consciente e determinada de produção de pães de legumes e bolachas produzidos com ingredientes orgânicos e/ ou agroecológicos ${ }^{2} \mathrm{e}$, ainda, por participar da feira agroecológica municipal e do circuito da Rede Ecovida, sendo reconhecido nesses espaços.

Buscou-se fazer uma análise qualitativa da realidade e da trajetória desse grupo de mulheres. A pesquisa qualitativa é, segundo Rodrigues (2007), aquela que investiga os problemas em seu ambiente natural, analisando os dados fornecidos pelas atividades e as interações cotidianas. Pode ser entendida como uma pesquisa descritiva, na qual se constrói a relação entre as variáveis, e também explicativa, ao levantar explicações sobre a situação encontrada (Gil, 2007).

Esse estudo pode ser classificado, segundo Gil (2007), como estudo de caso um estudo profundo de determinada realidade, investigando a situação dentro do seu contexto. Essa forma de pesquisa utiliza mais de uma técnica, a fim de se obter da- dos mediante procedimentos diversos e garantir a qualidade dos resultados obtidos, que tragam luz e favoreçam a descrição, a explicação e a compreensão do grupo estudado.

Uma das técnicas de levantamento de dados foi a observação não participante do dia a dia do trabalho das mulheres, a fim de captar relações sociais que fazem parte de seu cotidiano e que só podem ser observadas na realidade em que acontecem. Outro instrumento utilizado na coleta de informações foram entrevistas semiestruturadas realizadas com as mulheres, seus cônjuges e lideranças do grupo de agroecologia, concedidas à pesquisadora. Dessas fontes de informação foram retirados elementos importantes para compreender o contexto das mulheres dentro da agroindústria, seu cotidiano e suas experiências vividas nessa realidade.

Para garantir o anonimato, todos os nomes aqui apresentados são pseudônimos escolhidos pela autora da pesquisa, que assim esquematizou: Janaína: informante-chave, uma das lideranças do grupo de mulheres; Cláudio: companheiro de Janaína, uma das lideranças do acampamento; Francisco: coordenador do grupo de agroecologia do acampamento; Vanda e Paulo: família entrevistada 1; Fabiana e Roberto: família entrevistada 2; e Poliana e Geraldo: família entrevistada 3. A escolha dos casais que participaram da pesquisa se deu por sorteio, e a das lideranças e da coordenação entrevistadas ocorreu por escolha dirigida de algumas pessoas, tendo-se como critério a preferência por pessoas que pudessem contribuir melhor com a história do grupo e do acampamento.

\footnotetext{
2 Ingredientes orgânicos são aqueles produzidos sem a utilização de insumos químicos e agrotóxicos, substituindo insumos químicos por insumos orgânicos, mudança de técnica de produção sem nenhuma reflexão sobre o atual sistema agroalimentar e suas consequências sociais. Para a produção de ingredientes agroecológicos é preciso seguir premissas básicas da agroecologia, em que a mudança da tecnologia leva em consideração não só o respeito aos agroecossistemas locais, mas também a compreensão de que a agricultura envolve processos sociais integrados a sistemas econômicos, exigindo tratamentos mais equitativos a todos os atores, produtores, consumidores. Para melhor entendimento dessa diferença sugere-se a leitura de Caporal \& Costabeber (2004).
} 
O áudio das entrevistas foi gravado com consentimento dos sujeitos, o que garantiu o relato fiel $^{3}$ do que foi dito, e a transcrição delas, feita pela própria pesquisadora, o que permitiu a ela poder registrar suas impressões, os "não ditos" e as contradições das falas. Em seguida, as respostas foram separadas por categorias baseadas em temas e interpretadas de acordo com a análise de conteúdo (Bardin, 1977).

\section{Resultados e discussão}

Todas vestidas de branco, toucas nas cabeças e "mangas arregaçadas" na "lida" de produzir os pães de legumes agroecológicos. Nas expressões era possível observar o orgulho de estarem construindo uma história bonita de autonomia e participação, convictas de contribuir para o desenvolvimento da comunidade e do meio ambiente e para a saúde não só de suas famílias, mas também das pessoas para quem vendem seus produtos, como demonstram em seus depoimentos.

Janaína: É diferente você saber que está produzindo tanto pro consumo como para os outros comerem. É um produto que não é um produto, você está produzindo comida mesmo, produzindo alimento que pode comer com segurança. Tem também uma outra questão além de produzir e fazer renda.

Vanda: Pra mim, é pra saúde em primeiro lugar, da gente e das pessoa que vão comer esses produtos.

Fabiana: Agora assim a gente tem mais visão, porque as pessoas lá de fora estão enxergando nós aqui. É bom, porque agora todo mundo conhece o nosso acampamento, conhece o que nós estamos fazendo aqui dentro de bom. É isso que eu digo de mais visão, agora todo mundo está enxergando melhor a comunidade. Não é só mais um "onde é que fica esse lugar?" (risos). Agora as pessoas já conhecem: "Ah. Recanto, nossa, já estive lá. É bonito. As mulheres lá produzem pão, tem cada coisa boa" (risos). Esse tipo de coisa.

Já com uma longa espera para se tornar assentamento, a partir de 2006, um pequeno grupo do acampamento, composto de seis pessoas, decide abolir de vez o uso de agrotóxicos e outros insumos químicos que vinham não só endividando as famílias como também trazendo graves problemas de saúde à comunidade. Com essa definição, eles queriam garantir a sobrevivência e a permanência desse pequeno grupo no acampamento.

Foram fortalecidas as estratégias de cooperação entre as famílias no processo de trabalho, de maneira que as plantações nas unidades produtivas familiares fossem feitas de modo coletivo (mutirões), com constantes trocas não só de dias de trabalho, como também de saberes que permitiam o processo produtivo agora longe da utilização dos insumos químicos. Aqui, ressalta-se que fazer parte do MST facilitou esse processo organizativo já muito estimulado pelo movimento.

Francisco: Aí, quando eu vim pra cá, eu trabalhei dois anos no convencional e vi também que não funcionava, não era aquilo que teria que ser, não dava retorno nem financeiro e muito menos ambiental. Ai nós fizemos uma parceria com os piá que trabalhava ali: "Aí eu trabalho junto com vocês, usamos o meu lote também". Ai dividimos as coisas.

\footnotetext{
3 Foi mantida na transcrição a forma como falam os agricultores(as), com seus erros de concordância, gírias e maneirismos.

4 Piá: sm. 1 Índio muito jovem.2 Jovem mestiço de índio com branco.3 Reg (RS, SC) Qualquer menor que não é da raça branca e trabalha como peão de estância.4 Reg (MA), Zool V alma-de-gato, acepção ETIMOLOGIA tupi pyá.. Disponível em: $<$ http://michaelis.uol.com.br/bu $\mathrm{sca} ? \mathrm{r}=0 \& \mathrm{f}=0 \& \mathrm{t}=0 \&$ palavra=pi\%C3\%A1>. Acesso em: 26/12/2016. Na região da pesquisa, utiliza-se a palavra piá para se referir a qualquer menino ou rapaz jovem.
} 
Vanda: E a gente queria também baratear o custo da produção, porque do jeito que tava indo a gente só se endividava e não conseguia fazer nada. A gente faz pouco hoje, a produção da gente é bem pouca, mas a gente não tem custo, né? Produz do jeito que a gente pode, né? Ee é coisa boa, você come sem medo de que vai fazer mal.

Paulo: Eu acho que a gente, não só a gente como tem um grupo de famílias aqui que é assim como se fosse um fertilizante: ajuda o outro pra que você possa se enraizar cada vez mais e crescer mais. [...] Servir de exemplo, um exemplo bom, um exemplo construtivo de saúde, de viver mais tempo, ser útil, preservar a água, preservar a natureza, ter o trabalho como uma coisa importante, mas não ver o trabalho como uma forma de você se judiar e judiar o outro, mas você saber que tudo do trabalho origina frutos. Esse esforço tem essa vantagem: se educar para que daqui a alguns anos seja diferente de agora.

A partir de 2010, a proposta da agroecologia veio somar a esse grupo, que já tinha em sua formação inicial ideias de preservação do meio ambiente, cuidado com a saúde das pessoas, produção voltada mais para a subsistência da família do que para o mercado e trabalho mais coletivizado. Esse caráter se aproxima muito do modo de vida camponês, descrito por autores como Wanderley (1996), Horácio de Martins Carvalho (2005) e Sevilla-Guzman \& Molina (2013), entre outros.

Francisco: E foi feito uma reunião aqui [com técnicos do Ceagro ${ }^{5}$ ], dai eu fiquei responsável pra ir atrás de mais gente, mais familia que tinha o interesse de trabalhar a agroecologia, mas uma agroecologia que nem nós não sabia o que era realmente. Nós sabia que a agroecologia era não passar veneno e aquilo, pronto! Não passar veneno e nem usar adubo químico. Até ali era o que nós entendia e era o que de melhor nós sabia fazer, também já tinha apanhado bastante!
Junto a essa primeira articulação do acampamento com a agroecologia, começa a surgir na região uma discussão para a criação do hoje já estabelecido Núcleo Regional da Rede Ecovida Conquista Camponesa. Dentro desse novo cenário, o grupo de agroecologia, por meio da práxis - a teoria incluída na prática começa a se fortalecer dentro do acampamento. A organização interna, os mutirões e o entendimento de que a agroecologia vai além do "não passar veneno" corroboram a afirmação de Duarte (2009) para a produção de agroecossistemas sustentáveis. A agroecologia, como ciência e prática, entra, nesse sentido, para fortalecer o desenvolvimento rural, fundamentando-se na perspectiva de "transformação da sociedade" para mudar as relações de produção no campo.

Hoje são dez das 17 famílias no total que estão inseridas na estratégia de desenvolvimento rural sustentável da agroecologia no acampamento. Dentre as atividades desenvolvidas pela comunidade, possibilitadas pela certificação participativa da Rede Ecovida, destacam-se: a produção de leite orgânico e mel, a feira agroecológica que acontece duas vezes por semana no centro do município de Laranjeiras do Sul e, ainda, a agroindústria das mulheres, que fabrica pães e bolachas. Esta última, objeto deste estudo.

O grupo de mulheres do Recanto da natureza é composto de dez moradoras do acampamento, todas elas mães, agricultoras e inseridas tanto no trabalho doméstico e de cuidado quanto no trabalho produtivo dentro da unidade produtiva familiar. Estão, ainda, à frente da agroindústria ligada à Associação de Pequenos Agricultores do Assentamento Recanto da Natureza - Terra Livre desde 2014, quando a agroindústria foi fundada.

\footnotetext{
5 Ceagro: Centro de Desenvolvimento Sustentável e Capacitação em Agroecologia, uma organização não governamental ligada ao MST que presta assistência técnica em agroecologia.
} 
A agroindústria foi criada de maneira coletiva, visando a uma estratégia de desenvolvimento local do acampamento. Teve a participação tanto dos homens quanto das mulheres para a sua concretização. Entretanto, ela foi pensada principalmente como um espaço de trabalho coletivo para as mulheres do acampamento, que até então não tinham nenhuma atividade coletiva adaptada à realidade vivida por elas.

Segundo seus relatos, os espaços de trabalhos coletivos no acampamento sempre foram muito "masculinizados", conduzidos de forma e em horários que dificultavam a participação das mulheres, que estão absorvidas nas tarefas de cuidado e do cotidiano da casa. Outro aspecto que também foi levantado como dificultador eram os mutirões voltados para a implantação da atividade produtiva, contemplando apenas as partes "pesadas" dos trabalhos, nos quais as mulheres pouco se envolvem no seu dia a dia. Para a parte de manejo da atividade, da qual toda a família participa, não há nenhum processo coletivo pensado.

Janaína: [...] Acho também que é muito ligado pela questão de que quase todas as mulheres têm filhos, então alguém vai ficar na casa e é as mulheres que ficam. E aqui no acampamento e em outros lugares ainda é isso: eu vou ficar porque a Gisele [filha] tem escola, até meio-dia eu não posso ir. [...] Quando você vai somar no trabalho dos homens, você tem que ir a partir do que eles já definiram, você tem que se enquadrar e geralmente a gente não consegue se enquadrar no que eles definiram, porque eles definiram uma coisa que só favorece eles, não favorece as mulheres, não tem nem como a gente participar.

Vanda: [O espaço] das mulheres era só o clube de mães mesmo. Nem da associação, porque foi só agora que nós entramos, só agora que as mulheres entraram nesse grupo mesmo, da associação, porque antes era só os homens.
Fabiana: Me chamou a atenção porque em todos esses anos no acampamento não havia um grupo especifico para as mulheres do acampamento, a não ser o clube de mães, uma coisa assim voltada só pra mulher. Ai apareceu essa agroindústria e a gente viu bem claramente que a mulher tava tendo mais participação na comunidade, não só pela agroindústria, mas também pelos trabalho fora do acampamento, porque as mulheres saem, vai nas reunião de fora, como a Janaína, que sempre participa lá fora. Ela que traz todas as novidades pra dentro das mulheres, que leva a gente nos encontro. Que põe a gente nos curso. E antes não tinha isso, não tinha.

Esses depoimentos deixam claro que as mulheres, antes dessa organização coletiva de trabalho na agroindústria, ficavam isoladas, mais restritas ao espaço privado, executando atividades ligadas à reprodução da vida e aos cuidados com a família. Esse isolamento as mantinha longe dos espaços de decisão sobre os rumos do desenvolvimento da comunidade, além de favorecer a permanência da submissão da mulher ao homem, posições que as colocavam em situação de invisibilidade no meio rural.

De acordo com Burg (2007), a dificuldade em perceber o trabalho total da mulher do campo também é revelada nas fontes estatísticas oficiais, nas quais as mulheres não são cadastradas como agricultoras, tornando invisível o papel delas no desenvolvimento da agricultura familiar. Historicamente, pode-se afirmar que houve o não reconhecimento do trabalho das mulheres, seja o doméstico, seja o ligado às atividades relativas ao autoconsumo, como o do roçado, restringindo a autonomia econômica e política delas (Faria, 2011).

No Recanto da Natureza, com a gestão e a responsabilidade da agroindústria, veio a necessidade, já em 2015, de registrar as mulheres da comunidade como membros efetivos da associação dos moradores do acampamento, dando a elas a possibilidade 
de interferir nos rumos tomados pela associação e no processo de decisão sobre o desenvolvimento da comunidade, além de contribuir ativamente para que isso aconteça.

Francisco: Até teve aquela discussão, às vezes tem um projeto que é especificamente para as mulher, ai como que a associação ia acessar se na associação só consta o nome do homem? Já teve essa discussão também pra que no futuro, se tiver algum projeto que elas possam utilizar, até pra melhorar a condição da agroindústria, que tenha condições legais de elas fazerem isso né?

Poliana: Eu achei interessante. Até no começo, quando o Cláudio me chamou pra reunião assim, porque eu não tinha o costume de ir pra reunião, ia só o Geraldo. Eu dizia: "Vai o Geraldo. Indo um tá bom, né”. Até que eu fui participando. Assim que eu vi que era bem diferente de onde eu estava. [...] Até cheguei na casa eu comentei com ele: "Eu gostei muito daqui por causa de exigirem" [...] Daí, a última vez que ele veio [sozinho], ele falou: "A Janaina falou, a mulher do Cláudio cobrou de você não ter ido”. Ai eu falei:

"O errado é você, porque eu queria ir e você não quis me levar". [...] Nessa parte mudou muito porque é a participação dos dois, né? A participação de todo mundo, principalmente da mulher.

A participação nesses espaços, tanto no do trabalho coletivo na agroindústria quanto no das assembleias da associação, trouxe novas possibilidades, novas conquistas e avanços de certa forma políticos, que tiraram as mulheres da situação de invisibilidade e de isolamento, mesmo que algumas vezes essa participação ainda seja restringida pelos maridos que não conseguem ver o porquê de a mulher se dedicar a outras atividades que não as da esfera privada da casa, o doméstico (Faria, 2011).

Poliana: Se eu não me esforçasse de ir, talvez eu nem estivesse no grupo hoje, trabalhando com as mulheres. Tamo ali junto, porque na verdade eu sempre tive vontade de participar, de estar ali junto conversando. Desde amizade, conhecimento com as pessoas, até conhecimento das pessoas você não tem se está isolada na casa, trabalhando na roça, trabalhando na casa, mas você não tem conhecimento se você não tira um meio dia pra estar participando com a comunidade. Assim, eu quase não tinha conhecimento, porque eu não participava, ficava só no barraco.

Fabiana: Eu não conversava com as mulheres daqui, eu não frequentava a casa de ninguém, eu não ia em reunião, não fazia nada nessa parte. Eu estava bem afastada, não tinha muito convívio com ninguém. $E$ de lá pra cá que eu entrei e que mudou bastante foi essa parte. Eu me relacionei mais com as pessoas que eu não tinha muito conhecimento e nem relacionamento. Agora que eu tô participando eu vejo a importância que é estar saindo nesses encontros e fazer essas coisas lá pra fora, que antes eu achava que era uma bobagem. Como muitas ainda acham e não têm essa noção.

Mas a participação nos espaços públicos dentro e fora do acampamento trouxe também novos desafios, como gerir a agroindústria, lidar com cálculos e vencer a insegurança diante das dívidas de investimentos necessárias para garantia da produção como compra de equipamentos e capital de giro. "As questões de acesso ao crédito, comercialização, gestão, controle financeiro e administrativo ainda são muito identificadas como parte do mundo masculino, são percebidas como algo que elas não conseguirão manejar" (Faria, 2011. p. 51).

Elas já tiveram duas oportunidades de acesso ao crédito que as deixaram preocupadas com a dívida assumida. Elas não estão acostumadas com altas quantias de recursos financeiros e também nunca viram uma mulher administrar grandes valores monetários, pois geralmente só administram os valores que se referem aos gastos dentro de casa.

Duas das mulheres do grupo estão fazendo parte do curso de gestão de cooperativas, ofertado 
pelo Núcleo de Estudos de Cooperativas da Universidade Federal da Fronteira Sul (Necoop), do campus Laranjeiras do Sul, o que tem possibilitado que as próprias mulheres consigam compreender como se faz a administração de um empreendimento produtivo levando em consideração seus custos de produção, o capital de giro e também o cálculo das sobras que serão divididas entre elas.

Janaína: As mulheres têm muito medo. É processo de educação, é uma construção social, as mulheres aqui têm mais medo dos riscos, por exemplo, nós acessar o fundo de crédito e ficar devendo $R \$ 15.000,00 \ldots$ As mulheres nunca fizeram, pra pagar em duas parcelas as mulheres nunca fizeram, isso assusta! Mas, quando você vai contar isso pros homens, eles ficam assim: “Ahhh, não, isso é fácil, moleza!”, mas com as mulheres é diferente, elas se assustam bastante, assumem, mas é com muito medo, sabe?

Poliana: Minha preocupação era bastante de eu ir e não aprender nada. Que nem eu comentei: Eu ir? Eu falei que tinha vontade de ir, mas representa que minha cabeça não vai pegar nada e meu medo era eu ir lá participar e não conseguir trazer para as outras mulheres do grupo. A gente ficava meio assim, porque não entendia muito de número, essas coisas [...]. Daí agora, com a Vanda, nós participamos lá na segunda etapa do curso que teve, nós já pegamos bem, dai nós estamos fazendo a soma, eu e a Vanda, da quantidade de pão, os dias, somando tudo o que é gastado de gás, de massa, tudo, tudo.

O empoderamento pode ser observado como um dos principais ganhos de todo o processo participativo dessas mulheres. Empoderamento é, segundo Buendía-Martínez \& Carrasco (2013), o mecanismo pelo qual as pessoas passam a tomar conta de seus destinos, tendo consciência de sua capacidade e competência para administrar seus atos e suas consequências, dando um passo importante na construção de sua cidadania. Favorecem o empoderamento das mulheres o acesso aos recursos produtivos, as mudanças na divisão sexual do trabalho e a valorização social delas (Siliprandi, 2013).

\begin{abstract}
Janaína: Porque a gente deixou claro isso que, mesmo que a gente tenha bastante dificuldade, sofra pra aprender, a gente tem capacidade, então não precisa de algum companheiro ir lá fazer a finança e nós produzir, e que, se fosse desse jeito, nós também não ia querer. E hoje nós temos a Vanda, e a Poliana mais timidamente, mais a Vanda, fazendo todo o processo de gestão, controlando todos os cálculos. A Vanda tem $8^{a}$ série. Então nós conseguimos provar pra todo mundo, e pra nós mesmas que temos capacidade. Era até um pouco uma questão de honra pras mulheres provar que nós tinha capacidade.
\end{abstract}

Vanda: A gente participa, em primeiro lugar, porque a gente mora aqui na comunidade, então a gente tem que participar das coisas, né? E eu acho interessante, acho que ainda vai ajudar bastante nós ali do grupo. Por exemplo, a questão da renda. O pensamento é nós criar uma renda que dai nós podemos dizer que é nossa mesmo, né? Nós que conseguimos e nós que cuidamos.

Poliana: Eu acho que isso ajuda meio em tudo, né? Que desenvolve meio em tudo na família, com as pessoas, isso desenvolve bastante, vai ajudando a crescer e ficar forte, desde uma conversa, né? Participar é muito bom, né? A gente vai pra aprender, eu que estudei muito pouco, né? É bom porque a gente aprende e passa pro grupo. É muito bom participar mesmo! Comecei a participar e vou até o fim agora, porque é muito bom! Porque pra você pegar alguma coisa eu vi mesmo que você tem que ir e participar do começo ao fim pra você aprender! Então, estou gostando bastante!

De acordo com Cinelli \& Conte (2010), que descreveram o processo de construção da identidade feminista das mulheres do Movimento de Mulheres Camponesas (MMC - SC), na medida em que passam a ocupar outros espaços além das 
suas casas, elas refletem sobre os pressupostos nos quais foram socializadas, modificam a forma de se posicionar no mundo e com as pessoas ao seu redor, se dão conta das desigualdades de direitos em seu dia a dia, que antes eram vistas como naturais e, assim, começam a se questionar e a questionar a realidade vivenciada, compreendendo que o seu cotidiano pode ser diferente.

Na vivência com o coletivo, no trabalho fora de casa, é que as mulheres constroem e reconstroem suas identidades a partir das novas relações que elas estabelecem na comunidade. É, portanto, no trabalho da agroindústria que surge essa outra perspectiva que possibilita à mulher se transformar, por meio da identificação com o grupo, da autorrealização, do sentimento da autoestima e também da relação de novas culturas e novos contextos que thes são apresentados e que geram uma confrontação do real das relações sociais, provocando mudança de atitude e comportamento (Barros, 2009).

A identidade de constituir-se mulher é influenciada pela socialização, e estar na agroindústria, para essas mulheres, significa mais do que conseguir renda: é conhecimento, reconhecimento, conquista de espaço e valorização. $\mathrm{O}$ trabalho traz para elas novos parâmetros e valores do estar junto em todas as atividades e em todas as situações de trabalho, e nesse processo reconhecem a si mesmas, ao mesmo tempo em que são reconhecidas pelas outras (Barros, 2009).

Alguns depoimentos deixam claro que as mulheres passaram a ter consciência da contribuição de seu trabalho tanto para as unidades produtivas familiares quanto para a comunidade. A participação no grupo produtivo evidenciou a importância da produção do quintal para a renda das famílias, já que muito do que elas produzem no seu quintal hoje é vendido para a agroindústria, o que retorna em forma de renda para as mulheres e para a casa.
No início do funcionamento da agroindústria, esses produtos, como cenoura, batata-doce, chuchu, beterraba e mandioca, por exemplo, eram doados pelas mulheres, visando à viabilidade da agroindústria sob menor custo. O trabalho do quintal, ignorado pelo modelo econômico, passa a ganhar valor também. Torna visível a contribuição econômica das mulheres não só para a unidade produtiva, mas para o desenvolvimento da comunidade, mesmo quando este está fora da esfera mercantil (Faria, 2011).

\begin{abstract}
Vanda: Nós sempre temos essa compreensão com a comunidade, que quando precisa de uma ajuda a gente sempre tá disposto a ajudar. Se a gente tem a gente sempre leva, ajuda. Sempre que eu tenho e posso levar lá e ajudar, eu levo...
\end{abstract}

Poliana: Eu acho que sim, né? Desde a renda eu acho que vai ajudando, apesar de a gente não receber já, eu acho que vai ajudar e é uma forma de incentivar mais a gente. Apesar de que eu gosto, né? Qualquer serviço que envolver eu gosto, eu gosto de trabalhar no grupo. E eu acho que desde a renda vai ajudar também, apesar de que a gente trabalha um pouco mais, mas mais tarde vai vir a recompensa.

Janaína: A gente já discutiu dentro do grupo que nós compramos as coisas aqui das famílias, tipo mandioca pra fazer o pão, nós compramos ovo, nós compramos leite e nós discutimos que só vamos fazer os pagamentos para as mulheres. É a familia que está vendendo, mas nós só acertamos a compra com a mulher e depois vamos fazer o pagamento pra ela. Nós já estamos conseguindo fazer, através da produção, um outro processo de construção.

A agroindústria também constrói novas possibilidades produtivas ao seu redor, à medida que as famílias começam a adaptar a sua produção para abastecê-la. Esse estímulo que a agroindústria realizou fez com que a produção dos quintais se 
transformasse em renda direta, possibilitando seu remanejamento em maior escala. Isso evidencia que as mulheres sempre estiveram envolvidas nas diferentes etapas da produção, preparação e consumo de alimentos (Menasche \& Krone, 2012).

Janaína: Ai tomamos a decisão de transformar a agroindústria em agroecológica, pedir a certificação e aí agora ela está inclusive com os pães aí. Então a gente começou a correr atrás porque não tinha matéria-prima pra fazer pão, nós não tínhamos farinha, né? Ai nós começamos a adaptar receita, fazer pão de mandioca, que vai menos farinha, e comprar mandioca. [...] Nós temos 11 receitas de pão, tudo a partir do que as famílias produzem. [...] E ai a gente começou a estudar as receitas, fazia e não dava certo, foi, foi, foi até que nós chegamos a esses pães que produzimos hoje, mandamos pra feira, mandamos pro circuito [Rede Ecovida].

Poliana: Nessa parte eu acho que mudou, desde a produção que nem assim, desde venda agora ali que a gente fornece também um pouco para agroindústria, a gente já plantou, né? Fizemos uma plantação de rama, então já dá uma preocupação de se produzir mais pra entregar, né? Porque agora tem remuneração, né? Antes era doado, agora já estamos anotando tudo pra pagar tudo. É uma forma da renda ir ficando aqui na comunidade, né? Ir pegando das próprias famílias e colocando dentro da agroindústria.

Esta pesquisa sobre grupo produtivo de mulheres camponesas tendo por base a agroecologia evidenciou como principal desafio, para essas mulheres e para a comunidade, a superação da naturalização da reprodução como tarefa exclusiva das mulheres (Siliprandi, 2011). As mulheres se apropriaram dos trabalhos produtivos integralmente, enquanto os homens não assumem os trabalhos domésticos na mesma proporção.
Poliana: No trabalho agora fica mais puxado, nos dias que a gente tá aí [em casa]. Porque, quando você pega um serviço, tem que acabar meio rápido, porque já tem aqueles dias marcados pra vocêfazer as coisas lá fora [agroindústria e cursos], então eu acho que aumentou o trabalho.

Vanda: Sabe como fica a casa nos dias que eu estou para a agroindústria? Uma bagunça, né? (risos) Quando a gente chega de tarde, faz um limpa (risos). Quando chego à tarde, tenho que fazer todas as atividades da casa e do lote! Às vezes eu pego e faço de noite, quando não tá muito frio. Mas aqui fica uma bagunça mesmo!

Fabiana: Uma ideia boa seria fazer uma escola infantil, pra criança, pra que a gente possa estar mais envolvida no trabalho. Porque tem muitas vezes que a gente não pode... Tipo assim, vem o técnico pra fazer algumas plantas dentro do lote, pra dar como exemplo pra gente fazer no terreno da gente, e a gente não pode ir porque tá ocupada cuidando da menina, ou tá fazendo outra coisa.

Evidencia-se aqui que o trabalho na agroindústria veio a se somar às demais atividades que as mulheres já mantêm em jornada dupla: o trabalho doméstico e de cuidados com a família e o trabalho agrícola, gerando uma sobrecarga ainda maior de trabalho.

Para Spink (2007), a palavra empoderamento pode esconder um viés quase imperceptível, porém muito importante, que é a negação do outro ao acesso ao poder pelo sujeito estudado. "O empoderamento das mulheres não é um problema das mulheres[...], é um problema dos homens e das mulheres inseridos e inseridas numa luta histórica de definição e redefinição de relações de gênero" (Spink, 2007, p. 321). Segundo o autor, o empoderamento deve ser entendido como resultado das circunstâncias e dos posicionamentos aprendidos 
pelas pessoas. Portanto, um processo de renegociação de relações.

As mulheres estarem organizadas e atuando ativamente na produção de alimentos e renda é muito importante para o reconhecimento de suas existências na comunidade, no local, mas, ao mesmo tempo, não se pode esquecer que quem tem o poder sob suas mãos decide até onde permite o avanço, quais espaços liberará para serem ocupados. A questão é que ainda persiste, no Acampamento Recanto da Natureza, uma escala hierárquica de poder dos homens sobre as mulheres, das atividades ditas masculinas sobre as femininas, que continuam efetivando o tratamento desigual para as diferenças entre homens e mulheres.

Aqui se percebe que ainda há amarras que precisam ser rompidas e que vão além da consciência que as mulheres passam a ter de sua capacidade e do saber fazer. Envolve a luta pela sua emancipação, sair das amarras da opressão e dominação a que estão submetidas (Freire, 1987; Spink, 2007). E essa emancipação se inicia no processo coletivo e depende da subjetividade e da forma como cada mulher participante foi e continua sendo influenciada pela cultura machista nos demais círculos sociais dos quais participa ao longo da vida (Lewin, 1970). Para cada mulher o espaço do grupo e as novidades que ele apresenta podem ser apropriados de maneira única, particular e singular (Barros, 2009).

É necessário, afirma Siliprandi (2011), que os trabalhos domésticos de cuidado sejam encarados como um trabalho necessário para a sobrevivência dos seres humanos e para a manutenção da unidade familiar, além de responsabilidade que deve ser compartilhada entre homens e mulheres na construção de uma sociedade mais justa e equitativa. Dessa forma, as atividades de cuidado (cozinhar, lavar, educar as crianças) não podem mais apenas ser concebidas como atividades privadas, necessitando ser tratadas e vistas primordialmente como sociais.

\section{Considerações finais}

As mulheres vêm questionando cada vez mais a industrialização e o livre-comércio, que provocam o empobrecimento da diversidade alimentar e destroem os modos de produção e de vida de milhares de pessoas. Essa forma de organização agrava a pobreza das comunidades rurais e as situações de fome ao restringir o acesso à alimentação pelo preço das suas ditas mercadorias.

As mulheres são sujeitos importantes na discussão sobre a soberania dos povos, a manutenção da cultura e o respeito à vida e ao meio ambiente, pois constituem o grupo mais afetado pelo peso do sistema agroalimentar atual, que altera e invisibiliza cada vez mais sua atuação na sociedade (Siliprandi, 2013). Ignorá-las é permitir que se construa uma outra forma de entender e organizar a produção com novas alternativas que continuarão desconhecendo a capacidade e a importância das mulheres na contribuição para o desenvolvimento e para a vida.

Com esta pesquisa percebeu-se que o Acampamento Recanto da Natureza tem conquistado, com a proposta de desenvolvimento rural baseado na agroecologia e com todos os desdobramentos advindos dela e da economia solidária descritos nesse artigo, avanços importantes para a questão do empoderamento das mulheres, como produção de renda, autorrealização, aprendizado e participação.

A visibilidade que elas conquistaram por meio da participação efetiva e coletiva sinaliza que é possível promover a quebra da vinculação do lugar delas apenas no espaço privado, reprodutivo e não reconhecido. Ao mesmo tempo, a contribuição das mulheres do acampamento no desenvolvimento 
da comunidade se apresentou como uma condição necessária para que elas fossem capazes de melhorar seu bem-estar, aumentando sua interação com a comunidade e reforçando o sentimento de pertencimento ao local.

Mas isso não basta e não parece ser o objetivo final a que almeja a agroecologia quando pauta a transformação social, com uma sociedade verdadeiramente justa e equitativa para homens e mulheres. Com a agroecologia, o acampamento avançou porque, ao construir a proposta de um grupo coletivo e produtivo visando ao empreendimento solidário, empoderou as mulheres do grupo. No entanto, ainda não as emancipou por completo, mantendo-as presas e sobrecarregadas pelo patriarcado.

Serem incluídas e visibilizadas somente ao adentrar o âmbito público, sem que se tenha feito um debate coletivo das relações de gênero, significou para as mulheres do acampamento uma sobrecarga de trabalho, pois elas continuam ocupando o lugar de submissão, desvalorização e invisibilidade de sua participação nas atividades do âmbito privado, indispensáveis para a manutenção diária da unidade produtiva familiar.

Ainda não se percebeu nada concreto no acampamento para o avanço nessa direção. A manutenção da responsabilidade feminina pelas tarefas domésticas e de cuidado, seu acúmulo com outras atividades, a ausência delas na maioria das discussões teóricas e práticas de implantação e manejo das atividades de produção agroecológicas e também o predomínio masculino nos espaços de decisão, seja no âmbito público ou privado do acampamento, apontam obstáculos que precisam ser enfrentados para se avançar na conquista de autonomia e igualdade para todos.
Lembra-nos Boaventura de Sousa Santos (2011) que todas as lutas emancipatórias que se apresentam na modernidade não podem ser encaradas como ponto de chegada, mas sim como ponto de partida para se pensar uma transição paradigmática. A economia solidária, o reconhecimento das atividades desenvolvidas pelas mulheres na agroindústria como importantes para o desenvolvimento local e o empoderamento não devem ser encarados como a solução para a sociedade hierarquizada e cheia de negação de acessos, mas sim como o pontapé inicial para a verdadeira busca da emancipação dos povos que já vêm sofrendo há séculos com as consequências de sua colonização.

Enfim, observou-se, por meio destes breves apontamentos de pesquisa sobre o grupo de mulheres do Acampamento Recanto da Natureza, que as estratégias da agroecologia e da economia solidária se mostraram importantes para garantir a participação dessas mulheres na comunidade, mas, sem um debate de gênero que envolva todos os atores no processo, podem não trazer a transformação social com justiça e equidade, já que a opressão de gênero é também produtora das mais profundas desigualdades na sociedade.

\section{Agradecimentos}

Um agradecimento especial às agricultoras e agricultores do Acampamento Recanto da Natureza por se disponibilizarem a participar desta pesquisa. À orientadora Josimeire Aparecida Leandrini e à co-orientadora Siomara Aparecida Marques pelo auxílio na revisão deste trabalho e à Coordenação de Aperfeiçoamento de Pessoal de Nível Superior (Capes) pela concessão de bolsa à autora. 


\section{Referências}

Barros, V. A. Trabalho na contemporaneidade: delimitações em um mundo de exclusão. In: Neto, F. K.; Oliveira, R. T.; Silva, R.O. (Orgs.). Subjetividade(s) e sociedade: contribuições da Psicologia. Belo Horizonte: Conselho Regional de Psicologia de Minas Gerais, 2009.

Buendía-Martínez, I.; Carrasco, I. Mulher, atividade empreendedora e desenvolvimento rural na América Latina e no Caribe. Cadernos de Desenvolvimento Rural, 10(72), 21-45, 2013.

Burg, I.; Lovato, P. E. Agricultura familiar, agroecologia e relações de Gênero. Revista Brasileira de Agroecologia, 2(1), 1522-1528, 2007. Disponível em: <http://www.aba-agroecologia.org.br/revistas/index.php/rbagroecologia/ article/view/6593/4898>.

Campos, C. S. S. A face feminina da pobreza em meio à riqueza do agronegócio: trabalho e pobreza das mulheres em territórios do agronegócio no Brasil. O caso de Cruz Alta/RS. Buenos Aires: CLACSO, 2011.

Carvalho, H. M. O campesinato no século XXI: possibilidades e condicionantes do desenvolvimento do campesinato no Brasil. Petrópolis: Vozes, 2005.

Christoffoli, P. I. Elementos introdutórios para uma história do cooperativismo e associativismo rurais no Brasil. Revista Cooperação na Agricultura, 169-187, 2015.

Cinelli, C.; Conte, I. I. Mulheres camponesas construindo sua identidade feminista. In: Anais eletrônicos do Seminário Internacional Fazendo Gênero 9. Florianópolis, 23-26 ago., 2010. Disponível em: <http://www.fazendogenero. ufsc.br/9/resources/anais/1278273729_ARQUIVO_CatianeCinelli-Textocompleto.pdf $>$. Acesso em: 05 abr. 2015.

Caporal, F. R.; Costabeber, J. A. Agroecologia: alguns conceitos e princípios. Brasília: MDA/SAF/DATER-IICA, 2004.

Costabeber, J. A. A transição agroecológica: do produtivismo à ecologização. In: Caporal F. R.; Costabeber J. A. Agroecologia e extensão rural: contribuições para a promoção do desenvolvimento rural sustentável. Brasília: MDA/SAF/DATER, 2007.

Duarte, L. R. R. Transição agroecológica: uma estratégia para a convivência com a realidade semiárida do Ceará.
Brasil, Fortaleza, Dissertação (Mestrado em Geografia) UFC, 2009.

Dowbor, L. Produtores, intermediários e consumidores: o enfoque da cadeia de preços. Revista Econômica do Nordeste, 45(3), 7-16, 2014. Disponível em: <http://www. bnb.gov.br/projwebren/Exec/artigoRenPDF.aspx?cd_artigo_ren $=1495>$.

Faria, N. Mulheres rurais na economia solidária. In: Butto, A.; Dantas, I. (Org.). Autonomia e cidadania: políticas de organização produtiva para as mulheres no meio rural. Brasília: Ministério do Desenvolvimento Agrário, 2011.

Faria, N.; Moreno, R. A trajetória das mulheres na luta contra o livre comércio e pela construção de alternativas. In: Silveira, M. L.; Tito, N. (Org.). Trabalho doméstico e de cuidados: por outro paradigma de sustentabilidade da vida humana. São Paulo: Sempreviva Organização Feminista, 2008. p. 11-26.

Freire, P. Pedagogia do oprimido. 17. ed. Rio de Janeiro: Paz e Terra, 1987.

Freitas, T. V. Experiências de socialização do trabalho doméstico na América Latina. In: Silveira, M. L.; Tito, N. (Org.). Trabalho doméstico e de cuidados: por outro paradigma de sustentabilidade da vida humana. São Paulo: Sempreviva Organização Feminista, 2008. p. 27-53.

Gaiger, L. I. A economia solidária diante do modo de produção capitalista. Cadernos CRH, 16(39), 181-211, 2003. Disponível em: $<$ http://www.cadernocrh.ufba.br/ viewarticle.php?id=171>.

Germer, C. M. A economia solidária: uma crítica marxista. Revista do Instituto de Estudos Socialistas, 14, 193-214, 2006.

Gil, A. C. Métodos e técnicas de pesquisa social. 2. ed. São Paulo: Atlas, 1987.

Gliessman, S. R. Agroecologia: processos ecológicos em agricultura sustentável. Porto Alegre: Ed. UFRGS, 2009.

Lewin, K. Problemas de dinâmica de grupo. São Paulo: Cultrix, 1970.

Maluf, R. S. J. Segurança alimentar e nutricional. Petrópolis, Rio de Janeiro: Vozes, 2007. 
Menasche, R; Krone, E. E. Comida e trabalho: um estudo sobre relações de gênero entre famílias rurais assentadas. In: Anais do $5^{\circ}$ Encontro da Rede de Estudos Rurais. Belém, 3-6 jun. 2012.

Morissawa, M. A cooperação agrícola. In: Morissawa, M. A história da luta pela terra e o MST. São Paulo: Expressão Popular, 2001. p. 230-234.

Rodrigues, R. M. Pesquisa acadêmica: como facilitar o processo de preparação de suas etapas. São Paulo: Atlas, 2007.

Rover, O. J.; Lampa, F. M. Rede Ecovida de Agroecologia: articulando trocas mercantis com mecanismos de reciprocidade. Revista Agriculturas, 10(2), 22-25, 2013. Disponível em: <http://aspta.org.br/wp-content/uploads/2013/08/ Agriculturas_JUN-2013.pdf $>$.

Santos, B. de S. A crítica da razão indolente: contra o desperdício da experiência. Para um novo senso comum: a ciência, o direito e a política na transição paradigmática. 8. ed., v. 1. São Paulo: Cortez. 2011.

Sevilla- Guzmán, E. La agroecología como estrategia metodológica de transformación social. 2007. Disponível em: <https://www.socla.co/wp-content/uploads/2014/ la_agroecologia_comoEduardo-Sevilla.pdf?iv=24>.

Sevilla-Guzmán, E.; Molina, M. G. Sobre a evolução do conceito de campesinato. 2. ed. São Paulo: Expressão Popular, 2013.

Sevilla-Guzman, E.; Montiel, M. S. Agroecología y soberanía alimentaria: alternativas a la globalización agroalimentaria. PH Cuadernos, 191-217, 2012.

Sevilla- Guzmán, E.; Montiel, M. S. Del desarrollo rural a la agroecología: Hacia un cambio de paradigma. Documentación Social, 155, 23-39, 2009.
Siliprandi, E. Agroecologia, agricultura familiar e mulheres rurais. Revista Brasileira de Agroecologia, 2(1), 845-849, 2007. Disponível em: <http://www.aba-agroecologia.org.br/revistas/index.php/rbagroecologia/article/ view/6427/4733>.

Siliprandi, E. Mulheres agricultoras no Brasil: sujeitos políticos na luta por soberania e segurança alimentar. In: Lagarde, M.; Valcarcel, A. (Org.). Pensamiento Iberoamericano: feminismo, gênero e igualdade. Madrid: Egraf, 2011. p. 169-183. Disponível em: <https://dialnet.unirioja. es/servlet/articulo?codigo $=3710909>$.

Siliprandi, E. Alimentação como um tema político das mulheres. In: Rocha, C. (Org.). Segurança alimentar e nutricional: perspectivas, aprendizados e desafios para as políticas públicas. Rio de Janeiro: Fiocruz, 2013.

Singer, P. Economia solidária: um modo de produção e distribuição. In: Singer, P.; Souza, A. R. (Org.). A economia solidária no Brasil. São Paulo: Contexto, 2000.

Sousa, A.; Neves, D. Economia solidária e trabalho: elementos para análise das políticas públicas de geração de renda e trabalho. In: Anais do I Circuito de Debates Acadêmicos IPEA, Brasília, 2011. Disponível em: <http://www.ipea.gov. br/code2011/chamada2011/pdf/area2/area2-artigo3.pdf >

Spink, P. K. Processos organizativos e ação pública: as possibilidades emancipatórias do lugar. In: Jacó-Vilela, A. M.; Sato, L. (Orgs.). Diálogos em Psicologia Social. Porto Alegre: Editora Evangraf Ltda, 2007. p. 315-328.

Wanderley, M. N. B. Raízes históricas do campesinato brasileiro. In: Anais do XX Encontro Anual ANPOCS. Caxambu, MG, 1996. 